\title{
EDUCOPÉDIA, UMA FERRAMENTA PARA ENSINAR GEOGRAFIA
}

\author{
EDUCOPEDIA, UNA HERRAMIENTA PARA ENSEÑAR GEOGRAFÍA
}

EDUCOPEDIA, A TOOL TO TEACH GEOGRAPHY

\author{
Renata Bernardo ANDRADE ${ }^{1}$ \\ Ana Claudia SACRAMENTO ${ }^{2}$
}

RESUMO: A presente proposta de trabalho teve como objetivo analisar como a plataforma Educopédia, referente à disciplina Geografia, criada em 2010 pela Secretaria Municipal de Educação da Cidade do Rio de Janeiro, pode contribuir para efetivar uma educação geográfica dos estudantes do ensino fundamental. A plataforma é online, contém aulas digitais em que estudantes e professores podem acessar atividades autoexplicativas de qualquer lugar e a qualquer hora. $\mathrm{O}$ uso das novas Tecnologias de Informação e Comunicação (TICs) apresenta crescimento e pode ajudar o estudante a desenvolver sua capacidade cognitiva para pensar os conceitos, os conteúdos e fenômenos geográficos. Como metodologia qualitativa de pesquisa foi utilizada a análise de conteúdo, na qual foi desenvolvida a análise da página e dos conteúdos de geografia de forma geral descritos. Como resultados das análises preliminares, pode-se constatar a importância do uso da plataforma, a partir do momento que o professor desenvolva outras práticas e atividades de aprendizagem durante as aulas de Geografia.

PALAVRAS-CHAVE: Educopédia. Ensino de geografia. TICs.

RESUMEN: La presente propuesta de trabajo tuvo como objetivo analizar cómo la plataforma Educopédia referente a la disciplina Geografía, creada en 2010, por la Secretaría Municipal de Educación de la Ciudad de Río de Janeiro, puede contribuir a efectivizar una educación geográfica de los estudiantes de la enseñanza fundamental. La plataforma está en línea, contiene lecciones digitales en las que los estudiantes y los profesores pueden acceder a actividades auto-explicativas desde cualquier lugar y en cualquier momento. El uso de las nuevas Tecnologías de Información y Comunicación (TIC) presenta crecimiento y puede ayudar al estudiante a desarrollar su capacidad cognitiva para pensar los conceptos, los contenidos y los fenómenos geográficos. Como metodología cualitativa de investigación se utilizó el análisis de contenido, en el cual se desarrolló el análisis de la página, y de los contenidos de geografía de forma general descritos. Como resultados de los análisis preliminares, se puede constatar la importancia del uso de la plataforma, a partir del momento en que el profesor desarrolle otras prácticas y actividades de aprendizaje durante las clases de Geografía.

${ }^{1}$ Universidade Estadual do Rio de Janeiro (UERJ) - Rio de Janeiro - RJ - Brasil. Mestranda em Geografia, UERJ/FFP. Professora da Prefeitura Municipal do Rio de Janeiro. E-mail: prof.renata.geo@gmail.com

${ }^{2}$ Universidade Estadual do Rio de Janeiro (UERJ) - Rio de Janeiro - RJ - Brasil. Professora Doutora em Geografia da Universidade do Estado do Rio de Janeiro, UERJ-FFP. E-mail: anaclaudia.sacramento@hotmail.com 
PALABRAS-CLAVE: Educación. Geografía. TICs.

ABSTRACT: The present work proposal had as objective to analyze how the Educopedia platform referring to the Geography discipline, created in 2010, by the Municipal Department of Education of the City of Rio de Janeiro, can contribute to carry out a geographic education of the elementary school students. The platform is online, contains digital classes in which students and teachers can access selfexplanatory activities from anywhere and anytime. The use of new Information and Communication Technologies (ICTs) is growing and can help students develop their cognitive ability to think about concepts, contents and geographic phenomena. As a qualitative research methodology, the content analysis was used, in which the analysis of the page was developed, as well as the general geography contents described. As a result of the preliminary analysis, it is possible to verify the importance of using the platform, as soon as the teacher develops other practices and learning activities during Geography classes.

KEYWORDS: Educopédia. Geographic education. ICT

\section{Introdução}

Num mundo globalizado, a expansão do uso de novas tecnologias no cotidiano ampliou os diferentes modos de acesso ao conhecimento disponibilizado na rede mundial de computadores. Para Santos (1996), a globalização constitui o estágio supremo da internacionalização, amplificação em sistema-mundo de todos os lugares e de todos os indivíduos, em diversos graus. Fomos rodeados nestes últimos anos por mais objetos do que nos 40 mil anos anteriores, mas sabemos pouco sobre a natureza tecnicizada tornando-se essa natureza abstrata. "Os objetos que nos sevem são objetos técnicos criados para atender finalidades específicas. Como a inovação é permanente ficamos ignorantes e indefesos”. (SANTOS, 1996, p. 19). De acordo com Santos (1996), o meio geográfico, que já foi meio natural e meio técnico, é hoje um meiotécnico-científico-informacional. “Assim instalam, as condições do maior lucro possível para os mais fortes, mas também as condições para a maior alienação possível para todos. Através do espaço a mundialização, em sua forma perversa, empobrece e aleija". (SANTOS, 1996, p.30).

Na educação escolar, esse fenômeno contemporâneo se fez ressentir, com a adoção de novas estratégicas educativas que viessem corresponder às exigências impostas pelo uso das novas tecnologias. Segundo Andrade et al. (2016), utilizar as Tecnologias de Informação e Comunicação (TICs) para ajudar o aluno a compreender sua realidade é 
um grande passo para que o mesmo possa entender o espaço geográfico de forma criativa e prazerosa. Dessa maneira, as TICs podem se tornar uma poderosa ferramenta para os docentes realizarem seu trabalho em sala de aula de forma mais criativa e dinâmica, se forem utilizadas de modo correto e coerente com as necessidades educacionais.

A partir de 2009, foi implantada na gestão do prefeito Eduardo Paes uma política educacional voltada para as novas tecnologias educacionais na cidade do Rio de Janeiro. Nesse contexto surgem as aulas digitais como reforço para a aprendizagem ou como inserção do indivíduo no ambiente escolar. No ano de 2010, a Secretaria Municipal de Educação, através da subsecretária de Projetos Estratégicos, pensou em uma plataforma composta por aulas digitais produzidas por professores da própria rede municipal de ensino. Desse movimento e, após estudar formas de estimular o aluno ao estudo, surge a Educopédia - uma plataforma online colaborativa de aulas digitais, onde alunos e professores podem acessar atividades autoexplicativas de forma lúdica e prática, de qualquer lugar e a qualquer hora. As aulas digitais incluem planos de aula, apresentações, fichas teóricas e testes.

Nessa conjuntura, a Secretaria Municipal de Educação do município do Rio de Janeiro, no estado do Rio de Janeiro (SME/RJ), investiu, durante um período, na compra de computadores e tablets para as escolas municipais. A "Educopédia", disponibiliza aulas online, que podem ser utilizadas pelos docentes em sala de aula, com o uso dos equipamentos eletrônicos adquiridos. A partir disso, o aporte de tais investimentos despertou um questionamento: a utilização da Educopédia, realmente, pode contribui no processo ensino-aprendizagem em Geografia?

No contexto contemporâneo, o crescente acesso, pelos estudantes, às diferentes redes sociais, bem como o uso, por longos períodos do dia, da Internet, lhes propicia o contato com inúmeras informações sobre os assuntos mais variados do Brasil e do mundo. Todavia, o aumento do acesso às diferentes tecnologias comunicativas e informacionais não representa e nem garante a assimilação e compreensão de contéudos. Com isso, a utilização dessas tecnologias deve ser mediada pelo professor de modo a valorizar o conhecimento prévio dos alunos, a fim de que se formem, adequadamente, os conceitos geográficos trabalhados na disciplina.

Na Educopédia cada aula possui temas, competências e habilidades contempladas nas Orientações Curriculares da SME/RJ e estão dispostas por disciplina em cada ano do ensino fundamental, dividindo-se em trinta e duas aulas digitais correspondentes às 
semanas do ano letivo. Assim, "o ensino de geografia inserido no contexto tecnológico pode enriquecer e dinamizar as aulas utilizando os recursos da Educopédia, auxiliando o processo ensino-aprendizagem com o objetivo de despertar a criticidade dos alunos" (LIMA; VELASQUEZ; CORDEIRO, 2015; NOGUEIRA; SAMPAIO, 2012).

A disciplina de geografia, no Ensino Fundamental $\left(6^{\circ}\right.$ a $9^{\circ}$ anos $)$, é de suma importância, pois, por meio dela, o aluno pode desenvolver o seu senso de localização e se compreender como parte do mundo em que vive. A geografia proporciona a aquisição e o aperfeiçoamento de determinados conceitos, que contribuem de forma significativa para o desenvolvimento do aluno, não só como indivíduo no seu meio ambiente, mas também como cidadão em seu meio social. Tais conceitos podem ser aproveitados nas séries iniciais, pois os conteúdos abordados nas aulas de geografia possibilitam desenvolver tanto os aspectos sociais quanto os físicos (CASTELLAR; VILHENA, 2010).

Assim, este trabalho tem como objetivo geral analisar o conteúdo da plataforma Educopédia, verificar se o mesmo contribui para ensinar geografia aos estudantes do $6^{\circ}$ ao $9^{\circ}$ ano de Ensino Fundamental. A metodologia empregada nesta pesquisa é qualitativa, com base na análise de conteúdo (ANDRÉ, 2103; MORAES, 1999) e com a análise da página da plataforma digital, na Internet, e dos conteúdos de geografia de forma geral descritos.

Dessa maneira, o uso da plataforma pode ser um recurso importante como forma de estruturar um referencial para o desenvolvimento e aplicação de uma proposta pedagógica, na construção do conhecimento geográfico. A pertinência da temática possibilita a discussão de novas metodologias para o ensino de geografia, ao se utilizar linguagens e ferramentas que propiciem a melhora e qualifiquem a aprendizagem crítica dos estudantes.

Para tal, o texto está dividido nas seguintes seções: a análise de conteúdo para pensar a Educopédia, a discussão sobre as tecnologias da informação e comunicação (TIC): sua importância no processo de ensino e aprendizagem, e por fim a Educopédia SME/RJ: TICs na formação do estudante das escolas municipais do Rio de Janeiro.

\section{A análise de conteúdo para pensar a Educopédia}


A metodologia de pesquisa qualitativa tem como objetivo analisar o objeto a partir de diferentes olhares, pois é pensado compreender os processos e as interpretações sobre o estudo, segundo ANDRÉ (2013). Segundo Moraes (1999), a análise de conteúdo constitui uma metodologia de pesquisa usada para descrever e interpretar o conteúdo de toda classe de documentos e textos. Essa análise, conduzindo a descrições sistemáticas, qualitativas ou quantitativas, ajuda a reinterpretar as mensagens e a tingir uma compreensão de seus significados num nível que vai além de uma leitura comum. Como método de investigação, análise de conteúdo compreende procedimentos especiais para o processamento de dados científicos. É uma ferramenta e um guia prático para ação, sempre renovada em função dos problemas cada vez mais diversificados que se propõe a investigar. Pode-se considerá-la como um único instrumento, mas marcado por uma grande variedade de formas e adaptável a um campo de aplicação muito vasto, qual seja, a comunicação.

Moraes (1999) argumenta ainda que a análise de conteúdo seja uma técnica para ler e interpretar o conteúdo de toda classe de documentos, que analisados adequadamente nos abrem as portas ao conhecimento de aspectos e fenômenos da vida social de outro modo inacessível. A matéria-prima da análise de conteúdo pode constituir-se de qualquer material oriundo de comunicação verbal ou não verbal. Contudo, os dados advindos dessas diversificadas fontes chegam ao investigador em estado bruto, necessitando, então, ser processados, para dessa maneira facilitar o trabalho de compreensão, interpretação e inferência a que aspira a análise de conteúdo.

Ao se pensar como analisar e interpretar o texto do site do Educopédia, a análise do conteúdo acaba sendo um elemento importante neste diálogo, pois o documento apresenta características que são próprias a ela. Ela faz com que seja analisada a "fala" e os textos, ou seja, ela se constitui um conjunto de métodos e de teorias que pretendem investigar quer o uso cotidiano da linguagem, quer a linguagem nos contextos sociais, desta forma interpretando as mensagens a serem compreendidas, MORAES (1999).

Desta maneira, a organização desta metodologia é constituída pela preparação das informações, como interpretar os conteúdos em unidades, categorizar ou classificar as unidades, a descrição e a interpretação. A análise foi organizada da seguinte maneira: a separação do documento do site com informações relevantes a respeito da plataforma, com a leitura e a separação as frases condicionadas ao texto da plataforma; no segundo momento, observar as frases que marcam o documento em si, tratar dos elementos que foram retirados do texto; no terceiro momento, a categorização que deve ser adequada à 
análise, como tecnologias, AVA, ensino e aprendizagem e geografia; no quarto momento, a análise descritiva em si, ou seja, a descrição de algumas frases da plataforma para a compreensão do que se trata o conteúdo que esta exibe, e no quinto momento, a interpretação desses dados, ou seja, quais são o significado e a importância do conteúdo para a educação e para o ensinar geografia, bem como a análise estrutural da plataforma. A pesquisa será realizada analisando o conteúdo de geografia contido na Educopédia.

\section{As tecnologias da informação e comunicação (TIC): sua importância no processo de ensino e aprendizagem}

Segundo Darido da Cunha; Bizelli (2016), estamos acostumados a nos referir à tecnologia apenas para computadores, televisão, celulares e artigos ligados à informática. O termo tecnologia engloba a totalidade de coisas que a engenhosidade do cérebro humano conseguiu criar em todas as épocas, suas formas de uso, suas aplicações. De acordo com esses autores, a linguagem digital mostrou novas perspectivas de comunicação, quebrando a antiga noção de fronteiras, garantindo novas formas de produção e propagação de informações e a interação e a comunicação em tempo real. A essa forma de ver o mundo deu-se o nome de NTIC, Novas Tecnologias da Informação e da Comunicação.

Dessas NTICs, ao longo do tempo, foram se incorporando ao cotidiano e ficaram simplesmente TIC: tecnologias da informação e da comunicação. (BELLONI, 2005). As TIC apontam para um novo direcionamento na organização social, propagando novos locais para troca, compartilhamento e divulgação de informações: o ciberespaço, para SANCHO (2006) e LÉVY (1998).

O termo TIC teria surgido da fusão de três grandes vertentes técnicas da atualidade, que são: a informática, as telecomunicações e as mídias eletrônicas. O significado do ensino mediado pelas TICs pode alterar as estruturas verticais (professor $>$ aluno) e lineares de interação com as informações e com a construção individual e social do conhecimento. "Os ambientes digitais oferecem novos espaços e tempos de interação com a informação e de comunicação entre os mestres e aprendizes" (KENSKI, 2008, p. 11).

Com o surgimento das tecnologias digitais, diversos conceitos foram introduzidos e modificados em diferentes espaços. No contexto educacional, a informação é o 
simples acesso de um determinado conteúdo, mas o conhecimento é o domínio teórico e/ou prático do assunto. Neste sentido, informação e conhecimento não são sinônimos e, para se gerar conhecimento, o indivíduo precisa contar com uma postura crítica, ativa e interventora diante da informação, incorporá-la, dar a ela significado e relevância diante do contexto que ocupa e de seus interesses. Segundo Kenski (2008, p.9), “a função das tecnologias não é revolucionar o ensino e a educação como um todo, mas sim a maneira como esta tecnologia é utilizada para a mediação entre professores, alunos e a informação. Esta pode ser revolucionária ou não".

Desta forma, os Ambientes Virtuais de Aprendizagem (AVA) são espaços de informação e design próprio que proporcionam uma interação educacional entre os seus participantes. Além disso, esses ambientes propiciam um processo colaborativo de aprendizagem mediada pelo professor, ao se oferecer recursos variados como áudios, vídeos, objetos de animação etc.

Segundo Galvão; Leite (2011), uma das principais exigências para sua eficácia é de que o ambiente permita uma intensa interação do aluno com o objeto de estudo, o que não significa apenas teclar ou escolher opções de navegação. $\mathrm{O}$ desenvolvimento do aprendiz só se dará se a interação ultrapassar essa situação, fazendo com que o objeto de estudo se integre à realidade do sujeito, desafiando-o e estimulando-o, ao se criar novas situações a serem incorporadas às estruturas cognitivas existentes.

A interação deve abranger não só o universo aluno e computador, mas preferencialmente o aluno e o professor, com ou sem computador. Um ambiente virtual deve permitir diversas estratégias de aprendizagem, adequando-se ao maior número de pessoas com diferentes perspectivas e interesses. Ademais, deve-se proporcionar aprendizagem colaborativa, interação e autonomia, potencializando-se, assim, a construção do conhecimento.

Não se pode negligenciar a influência que as tecnologias exercem no processo de aprendizagem em geografia e nem desconsiderá-las como ferramenta pedagógica. Em acréscimo, tampouco é possível acreditar que basta introduzir as TICs no ensino, sem um planejamento bem estruturado, para lograr o aprendizado pretendido, concordando com Kenski (2007).

Já Lucena e Funks (2000, p.20) afirmam: "Tanto faz o quadro de giz ou a web, a tecnologia usada há de ser referendado para poder fazer sentido". A técnica, por si só, não forma nem o professor nem o aluno. A técnica se diferencia da tecnologia, uma vez que a primeira "compreende um conjunto de regras apropriadas a dirigir eficazmente 
uma determinada atividade" (ABBAGNANO, apud LORENZETTI et al., 2012, p. 434). A tecnologia, por outro lado, relaciona-se à técnica de épocas e culturas pretéritas, distinguindo-se pela presença de ciência experimental, ou seja, uma técnica de base científica.

Disso decorre que as tecnologias educativas contemporâneas, por si só, não modificam a prática educacional, mas possibilitam que se estabeleçam novas formas educativas. Assim, o modo pelo qual aluno e professor se apropriam da tecnologia educativa pode possibilitar a aprendizagem do conteúdo, desde que para isso concorram ações eficazes nesse processo. Sobre as Tecnologias de Informação e Comunicação no ensino de Geografia alguns autores afirmam que, apesar da insuficiência dos recursos pedagógicos, os quais servem para auxiliar a ministração das aulas pelos professores, os laboratórios de informática podem ser um recurso favorável. Isso porque o computador e seus programas são uma alternativa para a renovação que o ensino desta disciplina exige.

A importância das TICs para Kenski (2008) está no processo de ação colaborativa no ensino, que pressupõe a existência de circulação intensa de informações e trocas visando o alcance dos objetivos previstos. Os novos processos de interação e comunicação no ensino mediado pelas tecnologias visam ir além da relação entre ensinar e aprender. Orientam-se para a formação de um novo homem, autônomo, crítico, consciente da sua responsabilidade individual e social, enfim, um novo cidadão para uma nova sociedade.

\section{Educopédia SME/RJ: TICs na formação do estudante das escolas municipais do Rio de Janeiro}

No início da gestão da Secretária de educação Cláudia Costin na SME/RJ, pensou-se em adaptar o currículo existente na rede municipal, o Multieducação, à realidade do século XXI, já que este primeiro foi escrito em 1996. Partindo do princípio que todo o aluno passa por avaliações externas e que o governo federal coloca à disposição de estados e municípios os Parâmetros Curriculares Nacionais, nas diversas disciplinas e segmentos da educação básica, a equipe da Coordenadoria de Educação escreveu as Orientações Curriculares, com o intuito de nortear o currículo interno de cada instituição de ensino integrante da rede. Seria uma forma de alinhar os descritores 
da Prova Brasil, os Parâmetros Curriculares Nacionais e o Multieducação, que, por ser um currículo aberto, encontrou interpretações equivocadas ao longo de sua existência.

Iniciou-se, em 2010, um novo movimento que parte da SME-RJ, objetivando oferecer um processo didático inovador, a proposta de implantação de uma escola que oferta oportunidade de o aluno acessar e trabalhar a construção de seu conhecimento. Esta proposta foi pensada de modo a alinhar teoria e prática. Para isso, foi criado um projeto de aulas interativas - a Educopédia. De acordo com a Secretaria Municipal de Educação, a proposta das aulas digitais para a Educopédia tem como finalidade aumentar a autonomia do aluno sobre o seu processo de aprendizagem.

A Educopédia em forma de projeto foi criada por professores selecionados da própria rede, considerando as Orientações Curriculares do Município do Rio de Janeiro. O projeto consiste em atividades que incluem temas/conteúdos, com as respectivas competências, divididas em trinta e duas aulas digitais, por disciplinas, correspondentes às semanas do ano letivo. Vídeos, animações, imagens, textos, podcasts, quiz e jogos estão inseridos nas atividades, seguindo um roteiro pré-definido em consonância com teorias metacognitivas. (NOGUEIRA; SAMPAIO, 2012).

De acordo com a SME/RJ, uma característica importante dessa experiência é a integração do currículo com o material didático utilizado para apoiar o trabalho do professor em sala de aula. O material educativo on-line é disponibilizado para alunos e professores da rede pública de ensino da cidade, que podem consultar essas informações de qualquer computador e a qualquer hora, através do endereço eletrônico http://www.educopedia.com.br.

Dessa forma, selecionam professores da rede para atuar como Educopedista (o professor que cria as aulas digitais), elegendo-o como o mediador mais importante entre o aluno e o aprendizado, referindo-se aos conteúdos das aulas digitais. Por outro lado, essa prática é criticada, pois se apresenta como se apenas o conteúdo digital fosse responsável pelo aprendizado do aluno, excluindo o professor de sala de aula que atua cotidianamente e conhece a realidade onde os alunos estão inseridos (LIMA et al., 2015). Segundo a SME/RJ, nas aulas digitais da Educopédia, o Educopedista será o mediador das atividades propostas aos alunos e terá como objetivo permitir que eles alcancem o aprendizado.

Embora nesta metodologia das aulas da Educopédia, o aluno seja o protagonista ativo em seu processo aprendizagem, é necessário que exista a figura do mediador para nortear esse caminho, atribuindo maior significado ao que é estudado, relacionando exemplos a 
exemplos do dia a dia, motivando e aguçando a curiosidade sobre o tema, levando os alunos à reflexão, incentivando-os à pesquisa constante, entre outros. (MANUAL DA EDUCOPÉDIA, 2010, p.5).

Destacam-se nas aulas os objetos de aprendizagem, que são todos os recursos utilizados para garantir o aprendizado nas aulas digitais: ilustrações, animações, vídeos, fotografias, jogos (games) e textos. Tais recursos devem ser utilizados visando ao aprendizado do tema da aula, e não somente para garantir a interatividade do aluno.

Referindo-se ao processo metodológico proposto para a realização das aulas da Educopédia, segundo a SME, foram pensados cinco momentos distintos, que representam o processo de aplicação e aprendizado de um novo conteúdo, bem como suas estratégias para cada momento. Para cada um desses cinco momentos, pensaram-se diferentes estratégias e recursos para promover a construção do conhecimento de forma significativa. Foi levada em consideração a construção do conhecimento e a busca pela autonomia na tomada de decisão e na resolução de problemas, oportunizando a conscientização do aluno pelo processo de aprendizagem e a construção realizada por ele durante as fases de acomodação do novo saber. (LIMA, et al., 2015).

No princípio houve uma pressão por parte de SME/RJ para a utilização da Educopédia em todas as escolas e aulas. Foram enviados para as escolas notebooks e instalados data-shows em todas as salas, porém as escolas não estavam preparadas. Vários problemas impossibilitaram o uso da plataforma: falta de estrutura física, fios condutores de energia, internet e treinamento para os professores. Acreditava-se que apenas se inserindo a tecnologia resultaria numa maior qualidade das aulas, porém, o método de ensino ainda seria o tradicional.

A Educopédia é um Ambiente Virtual de Aprendizagem (AVA), concebido pela Secretaria Municipal de Educação da cidade do Rio de Janeiro, em parceria com o Instituto Oi Futuro, segundo eles para tornar o ensino mais atraente para crianças e adolescentes. Para tal, oferece aulas digitais de todas as disciplinas do ensino fundamental, bem como material de suporte pedagógico aos professores. "A Educopédia alia a educação à tecnologia, Ela é clara, direta e intuitiva. É possível ensinar conceitos para os jovens através de jogos e passatempos que prendem a atenção e estimulam o raciocínio lógico" (Manual da Educopédia, 2010).

Define-se o AVA como um espaço na Internet formado pelos sujeitos e suas interações e formas de comunicação que se estabelecem através de uma plataforma, tendo como foco principal a aprendizagem. Entende-se por plataforma uma 
infraestrutura tecnológica composta pelas funcionalidades e interface gráfica que compõe o ambiente virtual de aprendizagem (BEHAR et al., 2007).

Descrição estrutural da plataforma:

A figura 1 apresenta a $1^{\mathrm{a}}$ página inicial com acesso por login e senha, para alunos e professores cadastrados, mas liberada para o acesso de visitantes, que têm liberdade para usar o conteúdo das aulas e acervo da biblioteca, podendo copiar, distribuir e transmitir a obra, desde que obedeçam às regras predeterminadas.

Figura 1: Página inicial da Educopédia
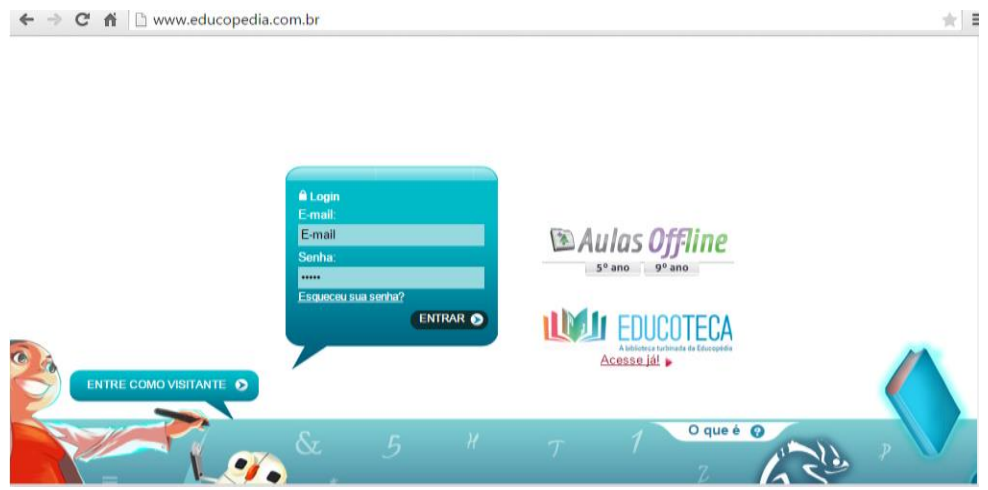

Fonte: http://www.educopedia.com.br/. 2015.

A figura 2 apresenta a $2^{\mathrm{a}}$ pasta com os nomes de todos os anos do ensino fundamentais que, ao serem clicadas, apresentam as disciplinas de acordo com a grade curricular específica de cada série.

Figura 2: Seleção do ano (série)

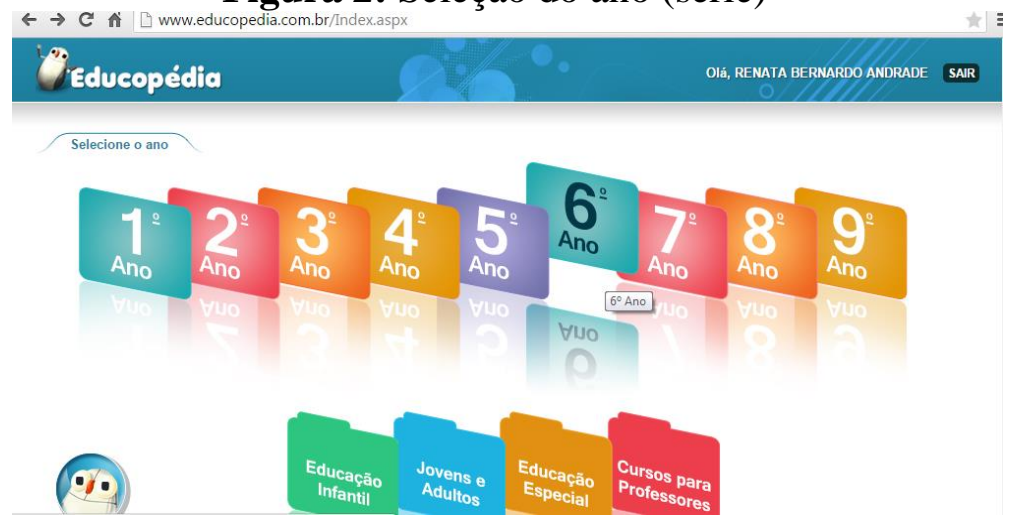

Fonte: http://www.educopedia.com.br/. 2015. 
A figura 3 apresenta a $3^{\text {a }}$ pasta com as disciplinas do ensino fundamental que, ao serem clicadas, apresentam a sequência das aulas, divididas em quatro bimestres, de acordo com a grade curricular específica de cada série.

Figura 3: Seleção da disciplina geografia

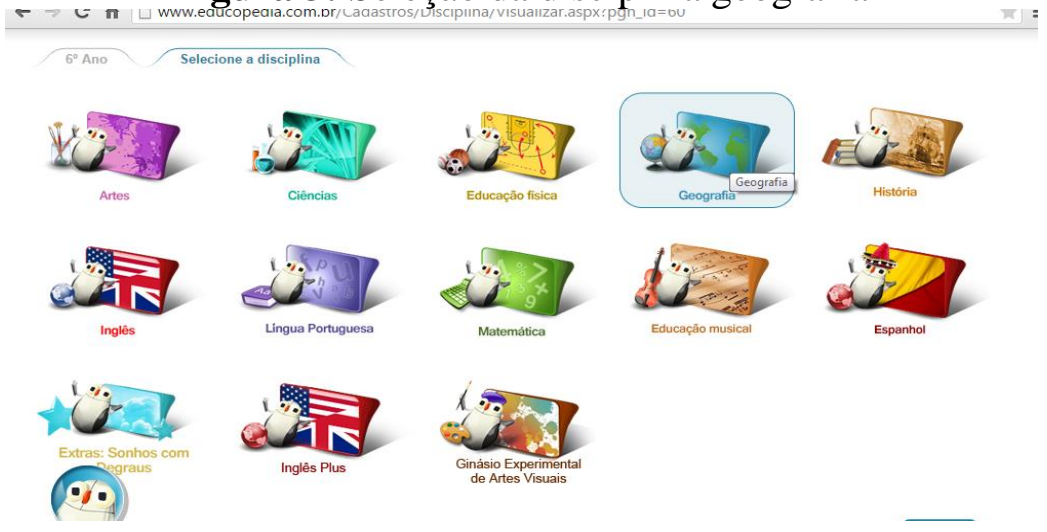

Fonte: http://www.educopedia.com.br/. 2015.

A figura 4 apresenta os links com as atividades referentes à disciplina Geografia.

Figura 4: Seleção do conteúdo sobre paisagem

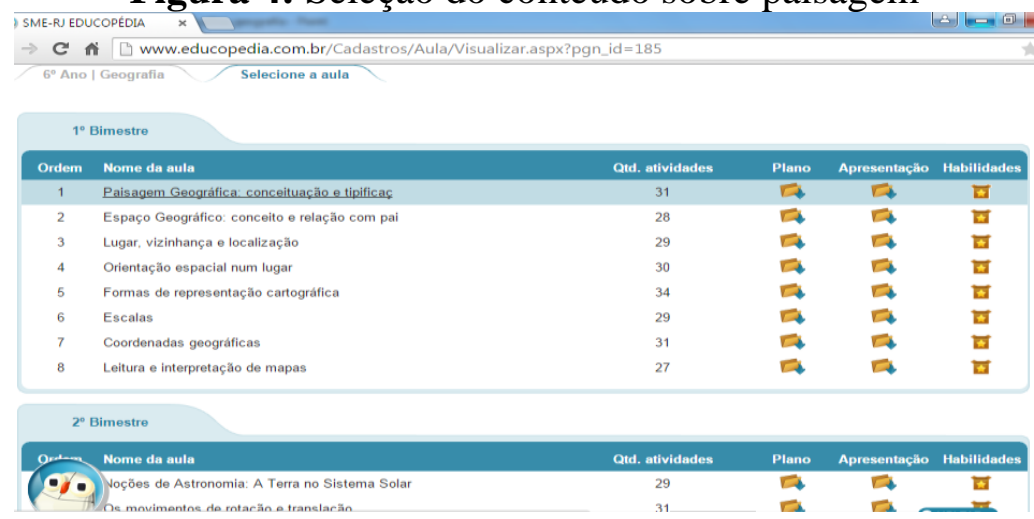

Fonte: http://www.educopedia.com.br/. 2015.

Dentre as funcionalidades de um AVA, pode-se citar, segundo Behar (2007), “características como a de comunicação síncrona e assíncrona, entre elas, bate-papo (ou chat), MSN, fórum de discussão, diários de bordo, base de dados, funcionalidades que dão suporte ao trabalho em grupo, publicação de arquivos, entre outros". O que se observa na plataforma Educopédia é que ela não é um AVA, embora o uso da tecnologia esteja presente, principalmente pelo próprio ambiente disponível na Web. Embora o ambiente seja apresentado como uma plataforma interativa e colaborativa, não há nenhuma evidência de que isso ocorra pela inexistência de bate-papo (ou chat), MSN, fórum de discussão, diários de bordo. O que predomina é o uso da tecnologia 
como recurso didático num paradigma tradicional de ensino, em que o aluno recebe informação e a processa isoladamente, para memorizar o conteúdo apresentado.

Atualmente, existem inúmeros AVAs que se propõem a dar suporte a processos de ensino-aprendizagem baseados na $W e b$, oriundos tanto do meio acadêmico quanto do comercial. Cada um deles possui, de forma implícita ou explícita, concepções sobre como ocorre este processo e servem para propósitos específicos.

Os recursos digitais disponíveis na disciplina geografia são os seguintes:

$1^{\text {o }}$ os softwares utilizados estão inseridos em atividades de leitura e audição, fixação e verificação da aprendizagem, como textos, áudios, exercício e prática, enciclopédia externa e arquivos em PowerPoint (PPT).

$2^{\circ}$ há uma tênue utilização de convergência digital, na medida em que vídeo, texto, áudio e imagem são utilizados no mesmo ambientes, tão somente como condutores de informação.

$3^{\circ}$ as ferramentas da web 2.0 se limitam a vídeos do youtube, links para páginas web e blogs externos.

$4^{\circ} \mathrm{O}$ ambiente não dispõe de recursos de comunicação síncrona e assíncrona nem ferramenta que permita atividades colaborativas.

Esses recursos sevem apenas para apresentação dos conteúdos geográficos de forma tradicional sem possibilitar uma reflexão e interatividade com os alunos. $\mathrm{O}$ professor que precisar entra como mediador do processo ensino aprendizagem para que os conteúdos de geografia estejam mais claros para os alunos.

\section{Ensinar a Geografia utilizando a ferramenta Educopédia no $6^{\circ}$ ano do ensino fundamental II}

De acordo com Oliveira e Moreira (2015), a combinação entre o Conhecimento Pedagógico e o Conhecimento do Conteúdo (geografia) resulta no Conhecimento Pedagógico do Conteúdo, que envolve o conhecimento de estratégias de ensino que incorporam metodologias adequadas para enfrentar as dificuldades do aluno. Também inclui o conhecimento prévio dos alunos essa combinação entre Conhecimento Pedagógico com o Conhecimento Tecnológico resulta o Conhecimento Tecnológico e Pedagógico, seria a compreensão de como usar determinados recursos tecnológicos com estratégias pedagógicas que favoreça o ensino de geografia. 
Ainda segundo os autores, da intersecção entre Conhecimento de Conteúdo e o Conhecimento Tecnológico, resulta o Conhecimento Tecnológico do Conteúdo, que seria o conhecimento sobre a maneira pela qual a tecnologia e o conteúdo estão relacionados. Da combinação entre as três categorias fundamentais do conhecimento resulta o Conhecimento Tecnológico Pedagógico do Conteúdo. Esse conhecimento enfatiza as relações existentes entre tecnologia pedagogia e conteúdo. (OLIVEIRA; MOREIRA, 2015). O conhecimento Tecnológico pedagógico do conteúdo, no caso a Geografia, ajuda a identificar componentes importantes do conhecimento dos professores que são relevantes para a integração das TICs na educação. O objetivo principal desse conhecimento é a conexão dos conhecimentos de geografia, pedagógico e tecnológico, que formam a base para sua estruturação.

Utilizar as TICs para ajudar o aluno a compreender sua realidade é um grande passo para que o mesmo possa entender o espaço geográfico de forma criativa e prazerosa. Dessa maneira, as TICs podem se tornar uma poderosa ferramenta para os docentes realizarem seu trabalho em sala de aula de forma mais criativa e dinâmica, se forem utilizadas de modo correto e coerente com as necessidades educacionais.

Para Munhoz (2006), pensar na aplicabilidade das TICs nas aulas de geografia não é simplesmente apresentá-las aos alunos. É relacionar o ensino e a aprendizagem significativa, a utilização destes recursos no processo de ensino-aprendizagem, permitir a articulação de diversos conhecimentos de forma interativa. Os empregos possíveis incluem desde o potencial de entretenimento, colaboração, interação, dentre outras características próprias de uma tecnologia, até a definição de quais conceitos serão trabalhados, passando em seguida ao planejamento, escolha dos objetivos a serem alcançados, metodologia e quais recursos digitais servirão a este intento.

De acordo com Callado (2012), os professores devem estar instruídos quanto ao uso dos recursos tecnológicos inovadores na disciplina de geografia, permitindo aulas mais atrativas tanto para os alunos quanto para os professores, possibilitando uma aula dinamizada sem fugir do contexto. Para o desenvolvimento das aulas de geografia, é importante o auxílio dos recursos tecnológicos encontrados na escola: utilização de vídeos/filmes, imagens, slides, músicas, blogs, fóruns, chats. O autor ainda ressalta a importância das imagens como recursos metodológicos para que os alunos, principalmente do ensino fundamental, consigam atribuir sentido ao aprendizado dos conteúdos geográficos. Podem-se utilizar fotografias, ilustrações, figuras até mesmo do livro didático, imagens de mapas, gráficos, tabelas, música, além da utilização da 
internet, que possibilita o acesso a todos estes recursos instantaneamente, ajudando o professor a dinamizar seu trabalho.

$\mathrm{Na}$ Educopédia, as atividades não se apresentam de forma atraente, mas apenas como uma seqüência didática bem tradicional com textos, vídeos, jogos e imagens, mas não de forma interativa. A plataforma em si tem problemas de estrutura, design, os conteúdos são tradicionais e não fazem de fato os alunos pensarem criticamente.

Por exemplo, em inúmeras aulas sobre o tema Paisagem, observa-se o quanto o tema é abstrato na cabeça dos alunos, de que as paisagens não são apenas lugares bonitos como os cartões postais da cidade do Rio de Janeiro. Não enxergam seu bairro, casa e escola como paisagem, porque segundo eles são lugares feios, desvalorizados, não se vêem como agentes transformadores da paisagem do seu espaço vivido.

A referência teórica do conceito geográfico da paisagem apoiou-se na definição de Santos (2008, p.73), que considera esta como "suscetível a mudanças irregulares ao longo do tempo, a paisagem é um conjunto de formas heterogêneas, de idades diferentes, pedaços de tempos históricos representativos das diversas maneiras de produzir as coisas, de construir o espaço”. No material disponibilizado nas aulas digitais sobre paisagem na Educopédia, começa-se relembrando os conceitos estudados na série anterior, como: Bairro, Lugar, Paisagem e Espaço geográfico. Não existem indícios que comprovem que houve efetivamente o estudo destes conceitos, haja vista que apenas uma professora deve dar conta de todos os conteúdos e existe uma exigência maior sobre as disciplinas de Português e Matemática, deixando assim a Geografia como disciplina secundária. Na seqüência, ao clicar em um ícone deveria aparecer um jogo sobre Paisagem, mas a página não está disponível. Após o jogo o aluno deveria identificar o assunto da aula; como não funcionou o jogo no próximo passo surgem as questões: O que é uma paisagem; Quais os tipos de paisagens que existem; Como observar o mundo que nos cerca. 
Figura 5: Início da aula sobre paisagem na Educopédia

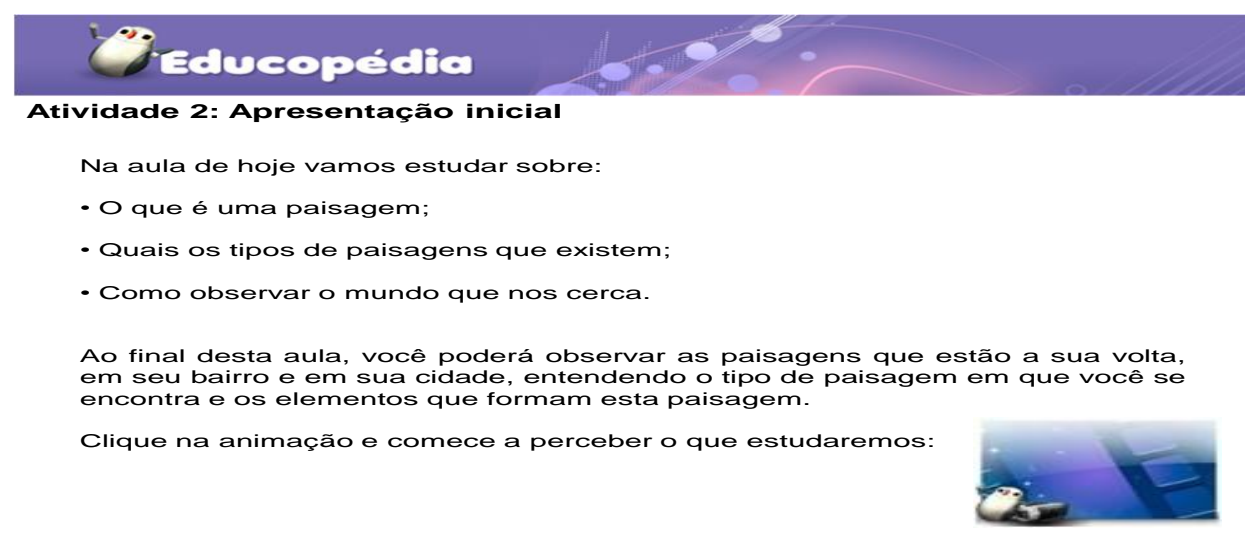

Fonte: www.educopedia.com.br

A exposição do conteúdo sobre Paisagem na Educopédia é estática e tradicional, não possibilitando de fato uma interação com os alunos, se apresenta apenas como um apertar de botão e troca-se a tela para outra que pode ter um texto, vídeo ou jogo, mas não abre para diálogo nem questões dos alunos. Para ilustrar o tema, uma animação utilizando uma foto aérea da Baía de Guanabara com pontos brilhantes; cada ponto que o aluno clicar aparece uma foto e uma informação para responder as questões anteriores. A definição utilizada na Educopédia de paisagem geográfica é tudo que a visão alcança, e procura mostrar que existem paisagens distintas e que estas são modificadas ao longo do tempo. A seguir, apresenta-se um vídeo do YouTube com o título de Subúrbio no trem, que ilustra uma viagem pelo subúrbio carioca, o que a visão alcança pela janela e no interior do trem, mas na escola o site do YouTube está bloqueado, desta forma não sendo possível utilizar este recurso.

Para demonstrar que existem diferentes paisagens, o site apresenta outro vídeo que também não assistimos com os alunos pelo motivo supracitado, chamado Os lugares mais bonitos do mundo, que sai da escala local para a global utilizando belas imagens de cartões postais de várias partes do mundo. Após apresentação inicial do tema inicia-se a avaliação por tentativa e erro da aprendizagem através do educoquiz com quatro questões para serem respondidas; se estiverem corretas, aparece instantaneamente parabéns na tela; se incorretas, surge infelizmente você errou e a resposta correta. 
Figura 6: Educoquiz

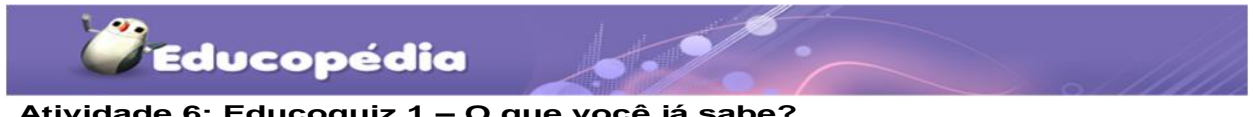

Atividade 6: Educoquiz 1 - O que você já sabe?

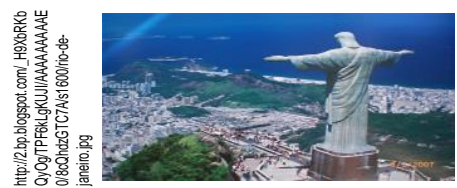

Por que é importante observar e analisar as paisagens?

a) Por que elas são muito bonitas;

b) Por que é a função da geografia;

c) Por que com isso podemos entender a realidade em que vivemos;

d) Para pintar belos quadros e contar belas histórias.

Fonte: www.educopedia.com.br

O Educoquiz é um jogo que se apresenta de forma tradicional, não interage com os estudantes, sem trazer uma reflexão sobre o que é Paisagem, apenas coloca uma questão para ser respondida por tentativas e erros e expõem um conteúdo; porém, se o aluno errar logo em seguida aparece qual seria a resposta correta, sem permitir a real aprendizagem dos alunos.

Figura 7: Comparação entre paisagens natural e cultural

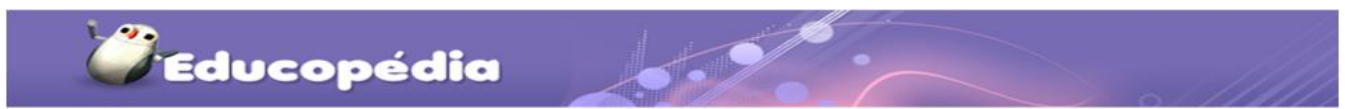

\section{Atividade 8: Momento de reflexão}

Temos aqui duas imagens semelhantes ao que você viu até agora, mas vamos parar para pensar um pouquinho e responder:

1 - Que nome você daria para a imagem 1?

2 - Que nome você daria para a imagem 2?

3 - As duas imagens representam uma paisagem. Você concorda com isso?
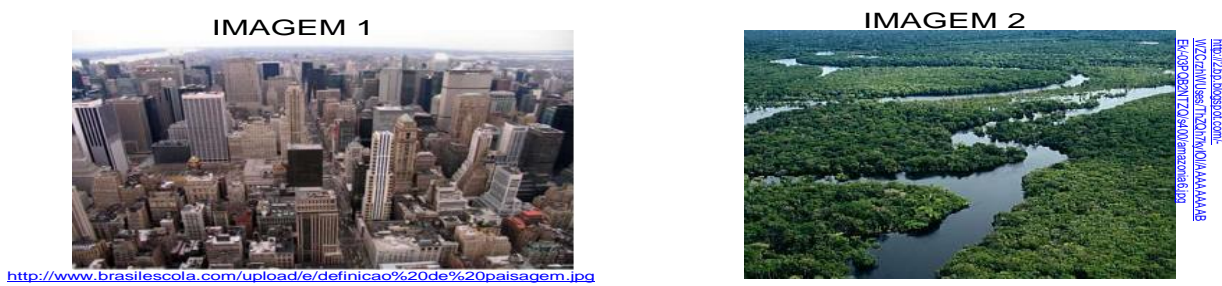

Fonte: www.educopedia.com.br

Apresentam os tipos de Paisagem: Natural, Humanizada ou Cultural e Transformada. Ela faz uso de outros vídeos para ilustrar cada tipo de paisagem. Além disso, disponibiliza um link para um jogo de identificação de paisagens naturais e humanizadas (de forma tradicional, sem uma reflexão sobre as mudanças na paisagem), 
depois utiliza outro vídeo sobre o BRT Transcarioca para mostrar as transformações e possíveis problemas causados na paisagem.

A Educopédia parece utilizar o conceito de paisagem do geógrafo Milton Santos (2008), que diferenciou paisagem de espaço geográfico com a seguinte citação em uma das aulas: Se jogarem uma bomba que só extermine os seres vivos, o que ficar será a paisagem, o espaço geográfico deixará de existir. Depois mais algumas perguntas do Educoquiz e uma proposta de atividade de criação de um quadro comparativo baseado nos elementos de cada paisagem e um desenho e cartaz sobre o aluno e sua sociedade e em como dependemos uns dos outros, um resumo escrito sobre tudo que aprenderam, e finaliza apresentando o tema da próxima aula.

A Educopédia pode ser um auxílio para o aluno buscar seu aprendizado através do processo de mediação do professor com os objetos de aprendizagem. Neste contexto, o professor de Geografia deve entender que a construção do conhecimento deve evidenciar a realidade dos alunos por intermédio de trocas de experiências e novas formas de participação. Assim, o professor deve mediar o conhecimento geográfico visando facilitar o processo ensino-aprendizagem, atento às mudanças que ocorrem além dos muros da escola, buscando desfrutar da realidade mais próxima do aluno e ampliando os conteúdos para que tenha uma aprendizagem mais efetiva. Para tanto, o aluno e o professor podem ter acesso às mesmas ferramentas da informação, a diferença está na forma como o aluno explora essa informação para obter o conhecimento e a maneira com que o professor a utiliza para ministrar suas aulas.

O aluno precisa ser orientado a interagir com a tecnologia de forma inteligente, por meio de textos, sons, imagens, animações, vídeos, programas do computador, desenvolvendo a habilidade de representar ideias com responsabilidade e respeito à privacidade dos dados e do ambiente de trabalhado com os colegas.

Assim, o professor pode inserir nos planejamentos de aula estratégias para que os alunos desenvolvam a criatividade e criticidade, usem linguagem e conteúdo apropriado na rede e na forma de se comunicarem. Por isso, é de grande relevância a construção do conhecimento geográfico voltado para capacitar e conduzir o aluno a elaborar a sua própria forma de conhecimento, a fim de atribuir ao educando o papel de intervir criticamente na informação obtida, transformando-a em conhecimento para aplicar como cidadão ativo na sociedade. 


\section{Considerações finais}

A proposta da Educopédia é permitir que os alunos tenham acesso aos conteúdos gratuitamente como apoio ou reforço dos estudos, mas a apresentação dos conteúdos continua de forma tradicional, de uma geografia descritiva com seqüências didáticas no site enfadonho. Como resultado inicial, os alunos ficaram surpresos e encantados com as imagens, animações, jogos e vídeos que abriram, mas pela falta de interatividade logo precisam ser estimulados pelo professor com tarefas e questões.

Foi questionado sobre como os alunos compreendem os conceitos geográficos como o de Paisagem; a maioria das respostas foi: um lugar bonito, uma praia, montanha, cachoeira, mesmo utilizando as ilustrações do site só fez sentido no entendimento dos alunos o conceito de Paisagem após o professor relacionar as imagens do site com o cotidiano e a paisagem ao redor da escola. Solicitei que os alunos descrevessem os elementos presentes na Paisagem ao redor da escola, realizando uma listagem e classificando em naturais ou humanizados. Esta etapa foi bem interessante, porque os alunos classificaram a horta como elemento natural, não como um construto do homem.

Em suma, a valorização dos conhecimentos prévios do aluno é fundamental para estabelecer ligações entre o cotidiano os conceitos geográficos expostos na Educopédia e ensinados na escola. Observa-se na plataforma Educopédia o uso da tecnologia presente, principalmente pelo próprio ambiente disponível na Web. Embora o ambiente seja apresentado como uma plataforma interativa e colaborativa, não há nenhuma evidência de que isso ocorra. $\mathrm{O}$ que predomina é o uso da tecnologia como recurso didático num paradigma tradicional de ensino, em que o aluno recebe informação e a processa isoladamente, para memorizar o conteúdo apresentado, como se pode perceber nas descrições elencadas neste trabalho. Diante dessa realidade, o uso da Educopédia como uma ferramenta a favor da educação tornou-se uma forma ilustrativa de trazer o conhecimento para dentro da sala de aula.

$\mathrm{O}$ professor como um mediador do conhecimento deve estar atento às melhores formas de inserir as tecnologias da informação e comunicação nas suas aulas, buscando assim desfrutar do melhor que elas oferecem para o bom aproveitamento da aprendizagem do discente. 


\section{REFERÊNCIAS}

ANDRÉ, M. E. D. A. Estudo de caso em pesquisa e avaliação educacional. Brasília: Liberlivro, 2013.

BEHAR, P. A.; PASSERINO, L.; BERNARDI, M. Modelos pedagógicos para educação a distância: pressupostos teóricos para a construção de objetos de aprendizagem. RENOTE, v. 5, p. 25-38, 2007.

BELLONI, M. L. O que é mídia e educação. 2 ed. Campinas, v.29. n. 104.

BIZELLI, J. L. Inovação: limites e possibilidades para aprender na era do conhecimento. 1. ed. São Paulo: Editora Unesp/Cultura Acadêmica, 2013.

BIZELLI, J. L.; HEREDERO, E. S. Educação e inovação: o desafio da Escola Brasileira. Revista Tendéncias Pedagogicas (Universidad Autónoma de Madrid), v. 28, p. 55-66, 2016.

CASTELLAR, S. VILHENA, J. Um breve referencial teórico e a educação geográfica. In: Ensino de Geografia. 1 ${ }^{a}$ ed. São Paulo, editora Cengage Learning, p.1-22, 2010.

CALADO, F. M. O ensino de geografia e o uso dos recursos didáticos e tecnológicos. Geo. Fort., v. 3, n. 5, p.12-20, jan-jun/2012.

DARIDO DA CUNHA, M.; BIZELLI, J. L. Caminhos para TIC em sala de aula sob a perspectiva dos professores. Revista on line de Política e Gestão Educacional, Araraquara, v.20, n.2, p. 282-300, 2016.

GALVÃO, M. C. A; LEITE, L. S. Educopédia: uma experiência em construção. ABED, RJ - maio, 2011.

KENSKI, V. Educação e tecnologias: o novo ritmo da informação. São Paulo, $2^{a}$ edição, 2007.

KENSKI, V. Novos processos de interação e comunicação no ensino mediado pelas tecnologias. In: Cadernos Pedagogia Universitária, USP, São Paulo: Pró-Reitora de Graduação, p. 1-22, 2008.

LEVY, P. A conexão planetária: o mercado, o ciberespaço, a consciência. São Paulo: Editora 34, 2004.

LIMA, L. G. R.; VELASQUEZ, F.; CORDEIRO, G. C. Contribuições da Educopédia para o processo de Ensino Aprendizagem. Art. Rio, v. 1, 2015, p. 1-12 .

LORENZETTI, J; TRINDADE, L. L; PIRES, D. E. P; RAMOS, F. R. S. Tecnologia, inovação tecnológica e saúde: uma reflexão necessária. Texto contexto - enferm. [online]. 2012, vol.21, n.2 [cited 2016-06-15], pp.432-439. 
LUCENA, C.; FUKS, H. Professores e aprendizes na web: a educação na era da internet. In: SANTOS, N. (org) Rio de Janeiro: Clube do Futuro, 2000. Disponível em: http://groupware.les.inf.pucrio.br/public/papers/2001. Acesso em: 27 mar. 2015.

MORAES, R. Análise de conteúdo. Revista Educação, Porto Alegre, v. 22, n. 37, p. 7 32, 1999.

MUNHOZ, G. B. A aprendizagem da Geografia por meio da Informática

Educativa. Dissertação defendida na Faculdade de Educação da USP. São Paulo: FEUSP, 2006.

NOGUEIRA, F. S.; SAMPAIO, F. F. Plataforma Educopédia: uma análise crítica do uso pedagógico de mídias digitais em seu ambiente. In: Anais do 18o. Workshop de Informática na Escola (WIE). Rio de Janeiro: NCE - UFRJ, s/p, 2012.

SANTOS, M. A Natureza do espaço - técnica e tempo, razão e emoção. SP, HUCITEC, 1996.

SANCHO, J. A tecnologia: um modo de transformar o mundo carregado de ambivalência. In: SANCHO, J. M. (Org.). Para uma tecnologia educacional. Porto Alegre: Artmed, 1998. p. 22-49.

SECRETARIA MUNICIPAL DE EDUCAÇÃO RJ; SECRETARIA DE NOVAS TECNOLOGIAS EDUCACIONAIS. Manual de metodologias digitais da Educopédia. Disponível em:

<http://www.educopedia.com.br/downloads/manualeducopedia.pdf>. Acesso em: 20 mar. 2017.

\section{Como referenciar este artigo}

ANDRADE, Renata Bernardo.; SACRAMENTO, Ana Cláudia. Educopédia uma ferramenta para ensinar geografia. Revista on line de Política e Gestão Educacional, Araraquara, v.21, n. esp. 1, p. 720-740, out./2017. Disponível em: <http://dx.doi.org/10.22633/rpge.v21.n.esp1.out.2017.10450>. ISSN: 1519-9029.

Submetido em: 20/06/2017

Aprovado em: 30/09/2017 